\title{
Gastrointestinal Disorders in Peritoneal Dialysis Patients
}

\author{
George Kosmadakis Julie Albaret Enrique da Costa Correia Frederic Somda \\ Didier Aguilera
}

Metabolic Pole and Department of Nephrology, Jacques Lacarin Vichy General Hospital, Vichy, France

\section{Keywords}

Gastrointestinal disorders · Peritoneal dialysis · CAPD

\section{Abstract}

Background: Gastrointestinal (GI) disorders in peritoneal dialysis (PD) patients are relatively understudied in the literature, even though they have a serious impact in the morbidity parameters and the quality of life for this group of patients. Various diagnostic tools have been used, including instrumental methods and questionnaires, invariably validated in comparative studies. Summary: The prevalence of Gl disorders is very high in PD patients. Compared to the haemodialysis patients they present a higher prevalence of reflux, eating dysfunction, gastroesophageal reflux, intestinal obstruction or adhesions and abdominal hernia. They may be divided into Gastric disorders (Gastroesophageal reflux disease, pathological Gastric emptying, Dyspepsia, Helicobacter pylori infection, peptic ulcers) and Intestinal disorders (Peritonitis, Diverticulosis, Constipation). Key Messages: The current paper is a review of the literature involving Gl disorders in PD patients. This special group of patients with a special role of the peritoneal cavity and the GI motil- ity in the physiology of their dialysis merit a larger number of studies dealing with the interrelation of the Gl tract and the PD physiological, functional and pathophysiological parameters.

(c) 2018 S. Karger AG, Basel

\section{Overview}

Gastrointestinal (GI) disorders in Peritoneal Dialysis (PD) patients are inadequately studied in the literature. The vast majority of studies on GI disorders affecting the renal patients do not categorize the haemodialysis (HD), $\mathrm{PD}$ and pre-dialysis patients in different groups. This strategy does not allow defining the effects of every particular dialysis technique on the type and severity of GI disorders.

The most prevalent symptoms in dialysis patients are constipation, indigestion, abdominal pain and reflux. Medication use and dietary data are generally poorly reported. The most common diagnostic tools are the GI Symptom Rating Scale (GSRS), Rome II and Rome III criteria. Constipation is more common in

\section{KARGER}

(c) 2018 S. Karger AG, Basel

E-Mail karger@karger.com

www.karger.com/ajn
Dr. George Kosmadakis

Pole Metabolique, Centre Hospitalier Jacques Lacarin Vichy

54 Boulevard Deniere

FR-03207 Vichy (France)

E-Mail George.kosmadakis@gmail.com 
Table 1. Diagnostic tools for the study of GI disorders in PD patients

Imaging methods

- Digital endoscopy direct methods with the use of tubular instruments for the upper and lower GI tract

(fibroesophagogastroduodenoscopy, colonoscopy, distal enteroscopy)

- Minimally invasive methods (colo-scanner, enteroscopy with micro capsule)

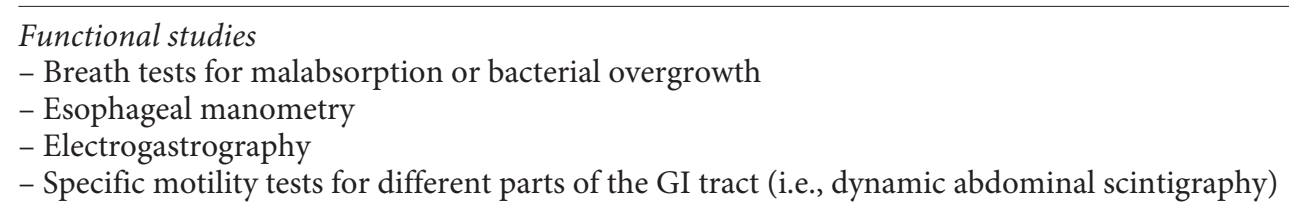

Questionnaires

- Gastrointestinal Symptom Rating scale (GSRS)

- GI symptoms questionnaire (GSQ)

- GIS or Gastrointestinal Symptom score

- Rome criteria (version IV)

- Bristol visual scale

HD patients than in PD patients. Indigestion, abdominal pain and reflux are common in both dialysis modalities.

In the present paper, we performed an in-depth narrative literature review based on data selected from an exhaustive search of various sources (DBLP, Google Scholar, ISI Proceedings, JSTOR Search, Medline, Scopus, Web of Science, EMBASE).

\section{Diagnostic Tools}

There is a multitude of diagnostic tools for the study of GI disorders in PD patients [1] (Table 1). The commonest in our days are the digital endoscopy direct methods with the use of tubular instruments for the upper and lower GI tract as well as indirect methods like the coloscanner for the investigation of the colon generally in patients with absolute contraindication for colonic endoscopy or the enteroscopy with micro-capsule. There are also functional studies evaluating the gastric, intestinal or colonic motility with radiologic or scintigraphy tools.

Questionnaires are also a very popular method despite the fact that there is a multitude of them in various clinical conditions. There is also some uncertainty concerning their validity in dialysis patients.

The GSRS is a self-administered questionnaire measuring GI symptoms in general with 15 items on 5 groups of GI symptoms and uses a 7-grade scale from $1=$ no discomfort to $7=$ very severe discomfort $[2,3]$.

Another tool is the self-administered GI symptoms questionnaire. With a development procedure similar to that of the GSRS, the GI symptoms questionnaire contains items selected on the basis of clinical experience and reports in the literature concerning the GI symptoms of dialysis patients [4].

GIS or GI Symptom Score is another questionnaire used for the evaluation of the GI disorders. It is a score with items including nausea, sickness, vomiting, bloating, abdominal cramps, early satiety, acidic eructation/heartburn, loss of appetite, retrosternal discomfort and epigastric pain/upper abdominal pain [5].

For constipation, 2 of the most popular criteria are the Rome criteria with regularly updated versions (currently on version IV) and the Bristol visual scale [6].

Bristol scale is widely used during the latest years as a diagnostic tool for the identification of constipated patients. A visual inspection of the stool with 7 different degrees of consistency (from 1 to 7 going from hard to smoother) is used as an evaluation tool independently of the Rome IV criteria. The consistency of the stool in this scale is representative of the intestinal transit time $[7,8]$.

\section{Prevalence}

The overall incidence of GI symptoms in PD patients is astonishingly high (Table 2). In a Chinese study with HD and PD patients, the overall prevalence of GI symptoms defined by a GSRS $>1$ differed between HD and PD patients. HD patients had a higher prevalence of constipation, abdominal pain and diarrhoea compared to PD patients. PD patients had a higher prevalence of reflux compared to 
Table 2. Prevalence of GI disorders in PD patients

\begin{tabular}{|c|c|c|}
\hline Study & Patients & Results \\
\hline Dong et al. [9], 2014 & $\begin{array}{l}182 \mathrm{HD} \text { and } 112 \mathrm{PD} \\
\text { patients }\end{array}$ & $\begin{array}{l}\text { GSRS }>1 \text { (HD: } 76.4 \text { vs. PD: } 61.6 \%, p<0.01) \text { HD }>\text { constipation, }(36.3 \text { vs. } \\
17.9 \%) \text { abdominal pain }(32.4 \text { vs. } 5.4 \%) \text { diarrhea }(17.6 \text { vs. } 4.5 \%) p<0.05 \\
\text { PD }>\text { reflux }(32.1 \text { vs. } 24.2 \%, p<0.05)[9]\end{array}$ \\
\hline Li et al. [4], 2009 & 214 PD patients & $57.93 \%$ with GI symptoms \\
\hline Salomon et al. [11], 2013 & $\begin{array}{l}122 \mathrm{PD} \text { and } 172 \mathrm{HD} \\
\text { patients interviewed by } \\
\text { a dietitian }\end{array}$ & $\begin{array}{l}\text { PD patients: }>\text { GI symptoms ( } 55 \text { vs. } 12 \%, p<0.001 \text { ). Reduction in food } \\
\text { intake ( } 53 \text { vs. } 14 \%, p<0.001 \text { ) changes in dietary habits to alleviate } \\
\text { symptoms ( } 34 \text { vs. } 9 \%, p<0.001 \text { ) }\end{array}$ \\
\hline
\end{tabular}

HD patients. Additionally, reflux and eating dysfunction were more severe in $\mathrm{PD}$ patients, whereas $\mathrm{HD}$ patients had greater abdominal pain, diarrhoea and constipation [9].

In a study from Li et al. [4], 214 PD patients were studied for the presence of GI symptoms. This cross-sectional study revealed that $57.93 \%$ of patients have varying degrees of GI symptoms.

The risk of gastroesophageal reflux, intestinal obstruction or adhesions, and abdominal hernia is significantly higher in the PD group. The risk of peptic ulcer disease, lower GI diverticula and bleeding is significantly higher in the HD group implying the effects of intradialytic ischemia and dialysis anticoagulation. Meanwhile, the risk of mesenteric ischemia, liver cirrhosis, and acute pancreatitis does not differ between the PD and HD groups; moreover, the risk of appendicitis in the $\mathrm{PD}$ group might be lower than that in the HD group [10].

In a study with dietician interviews, $85 \%$ of the patients on PD reported at least one GI symptom, compared with $51 \%$ on HD. Compared with HD, more PD patients reported that GI symptoms were related to the onset of dialysis. A greater number of PD patients (compared with HD patients) reported a reduction in food intake and changes in their dietary habits in an attempt to alleviate symptoms [11].

\section{Classification of GI Disorders in PD Patients}

\section{Gastric Disorders}

- Gastroesophageal reflux disease (GERD)

- Gastric emptying

- Dyspepsia

- Helicobacter pylori infection and peptic ulcers
Intestinal Disorders

- Peritonitis

- Diverticulosis

- Constipation.

\section{Gastric Disorders}

The most common gastric symptoms in PD patients are the GERD, dyspepsia and eating dysfunction $[12,13]$.

In patients undergoing $\mathrm{PD}$, the prevalence of eating dysfunction, reflux and indigestion is very frequent and may be observed in almost one third of the patients. A history of corticosteroid therapy and the number of pills taken daily are positively correlated to GI symptoms, while residual renal function was negatively correlated to GI symptoms [9].

Pathophysiological Mechanisms of Gastric Disorders The underlying pathophysiological mechanisms for these gastric disorders might be the following:

1. Delayed gastric emptying, which is common in renal patients. PD patients have longer gastric emptying time compared to pre-dialysis patients [14]. There is a clear association between the presence of glucosebased dialysate in the abdomen of PD patients and delayed gastric emptying [15]. Nevertheless, a number of studies found no obvious effect of the PD technique on gastric emptying [16-18].

2. Intraperitoneal pressure. There is no clear association between the levels of intraperitoneal pressure and the presence of GERD in PD patients [19].

3. Decreased lower esophageal sphincter pressure (LESP). There is a controversy over the effect of the presence of infused dialysate on LESP and esophageal reflux symptomatology. There are data associating upper GI symptoms and reflux episodes in infused PD patients with lower LESP and there are studies that 
found no systematic changes in intragastric or LESPs at any time of PD $[20,21]$.

\section{Gastrointestinal Reflux Disease}

GERD is frequently seen in PD patients. In a number of studies its prevalence is almost 3 times higher in PD patients than in HD patients and normal controls [22]. Dyspepsia is more common among PD patients compared with HD patients. The start of dialysis tends to have a greater impact on dyspepsia and GERS in PD patients than in HD patients. The proportion of patients on PPI treatment after the onset of dialysis may be high but does not differ between PD and HD patients [14].

Nevertheless, just like in the other symptomatic entities, other studies have not confirmed these outcomes. There have been studies that showed the prevalence of GERD in dialysis patients was higher than that in the controls, but there was no significant difference between PD and HD patients concerning GERD and the prevalence of erosive and non-erosive reflux esophagitis [23].

\section{Gastric Emptying}

Gastric motility is controlled by gastric myoelectrical activity, which propagates from the proximal body to the distal antrum at a frequency of 3 cycles/min. PD patients present a higher prevalence of early satiety than HD patients and there is a significant correlation between changes in tachygastria and grade of early satiety in $\mathrm{PD}$ patients with upper GI symptoms [24].

Gastric emptying is impaired in PD patients, regardless of the composition of dialysate and even when tested with an empty peritoneal cavity. Gastric emptying is significantly slower when glucose-containing dialysate is compared to an empty peritoneal cavity, or when glucose-containing dialysate is compared to icodextrin dialysate. No difference in gastric emptying could be demonstrated between glucose-containing dialysate and dialysate containing a mixture of glycerol and amino acids as osmotic agent. The additional delay in gastric emptying that has been demonstrated in the presence of dialysate might not be the consequence of a mere volume or pressure effect but at least in part due to the absorption of caloric and metabolically active substrate substances, such as glucose or glycerol and amino acids [15].

The absence of the effect on the reduced gastric motility due to the presence of indwelling dialysate has been confirmed in other studies [16].

It seems that there are some factors related to the renal insufficiency potentially responsible for the prolonged
GET. PD and transplant patients have equally longer GET compared to healthy controls [18].

\section{H. pylori Infection and Peptic Ulcers}

$H$. pylori infection is associated with anorexia, inflammation and malnutrition in PD patients. Eradication of $H$. pylori significantly improved this syndrome. Residual renal function seems to have a protective effect on appetite preservation [25].

The prevalence of $H$. pylori infection is highest in $\mathrm{HD}$ patients and pre-dialysis patients compared to $\mathrm{PD}$ patients. In contrast, the prevalence of dysmotility-like dyspepsia is higher in PD patients compared to the HD ones [26].

PD and CKD patients present with a significantly higher rate of Peptic Ulcer Bleeding (PUB) than healthy controls. The risk of PUB between PD and CKD is not significantly different. Moreover, patients on $\mathrm{HD}$ are on greater risk for PUB compared to the PD patients. Consequently, $\mathrm{CKD}, \mathrm{PD}$ and $\mathrm{HD}$ are independently associated with an increased risk of PUB [27].

The risk factors for peptic ulcers in dialysis patients are age, $\mathrm{PD}$, diabetes mellitus, congestive heart failure, low serum albumin and high gamma-glutamyl transpeptidase levels [28].

\section{Intestinal Disorders}

\section{Peritonitis}

GI symptoms are associated with increased risk for enteric peritonitis episodes. PD patients with peritonitis episodes present in general less GI symptoms, a lower dialysis vintage and a worse nutritional status compared to the ones without this serious complication, with belching and constipation, as the strongest predictors of peritonitis [29].

\section{Diverticulosis}

A major controversy exists concerning the association between colonic diverticulosis and the risk for enteric peritonitis. There are studies clearly associating the 2 entities and invariably associating diverticulosis involving the ascending colon as a significant risk factor [30]. The presence of colonic diverticulosis was once considered a relative contraindication to PD because of its association with enteric peritonitis [31, 32]. However, later studies from other Western countries found no such association [33, 34].

This may be due to the wide variation in diverticulosis prevalence and patient characteristics among different countries. Patients from the west hemisphere present more often with descending colon diverticulosis, whereas Asian patients show a higher frequency of ascending colon diverticulosis without a clear pathogenic explanation [30]. 
Constipation and Laxatives

The regular use of lactulose as an oral laxative is associated with a reduced rate of enteric peritonitis. There is no plausible explanation for this protective effect even though we can suspect a reduction in bacterial colonic translocation [35].

In other studies, treatment with Polyethylene glycol in a cross-sectional manner significantly improved bowel movement frequency and stool consistency in constipated PD patients [36].

The consumption of fibres either with the food or in form of supplements might reduce the consumption of aggressive osmotic laxatives [37].

\section{Constipation in PD and HD Patients}

HD patients had a 3.14 times higher relative risk of constipation than PD patients [38]. The much higher prevalence of constipation in HD compared to PD patients shows the discrepancy between the different rates and the unequal clinical consequences of this condition in these groups of patients.

In a study from China, with 605 dialysis patients, the incidence of constipation defined by the Rome III criteria was $71.7 \%$ in HD patients and $14.2 \%$ in PD patients who presented with a significantly worse health-related quality of life [39].

\section{Mechanisms of Enteric Peritonitis}

The mechanisms by which micro-organisms from the intestinal lumen gain access to the peritoneal cavity and cause enteric peritonitis may depend on 3 main factors: integrity of the intestinal wall, bacterial overgrowth status in the intestinal lumen, and host peritoneal defense. Acute inflammation, stasis, and obstruction of diverticula may lead to the translocation of enteric bacteria from the intestinal lumen into the peritoneal cavity [30].

Unfortunately, the notion of transmuric migration of intestinal flora provoking peritonitis of enteric origin and its risk factors is often based on old, small uncontrolled studies [40]. It seems like a subject that is considered well developed and known, but in reality it is based mostly on insufficient data.

The conservation of the stomach acidity might protect the intestinal microflora from dysbacteriosis and the increase in potentially pathologic enteric bacteria. Treatment with gastric acid inhibitors has been accused to be related with the development of enteric peritonitis [33] even though other studies have not confirmed this association [34].

\section{Other Situations Associated with GI Disorders}

\section{Psychological Factors}

A negative correlation has been shown between GI symptoms and psychological general well-being indicating that renal patients with a high GI symptom profile have impaired psychological general well-being [13].

\section{Electrolytic Disorders and Nutritional Status}

Between the risk factors for constipation in dialysis patients' electrolytic disorders is a frequent and underestimated condition [41].

Nutritional status is not very clearly associated with the GI disorders with conflicting results in the literature. In a study with PD patients presenting GI symptoms, there was no real association with the nutrition status evaluated by the subjective global assessment tool and other indices of nutrition (mid-arm circumference, skinfold thickness, daily protein and energy intake, handgrip strength, lean body mass, and serum albumin and prealbumin levels) [4].

On the contrary, other studies discovered that GI abnormalities were negatively associated with nutrition parameters in PD patients [42].

The later discrepancies are a clear example of the lack of solid data concerning this group of devastating clinical conditions.

\section{Conclusion}

In conclusion, GI disorders in PD patients are a frequent and often neglected pathological condition, affecting the dialysis technique and the quality-of-life parameters of this group of patients.

More studies with clearly defined reference values are urgently needed to elucidate the GI physiological adaptations taking place in the peritoneal cavity after the infusion of dialysate solutions with variable volumes and consistency. We also need to know much more on the choice of diagnostic tools and the pathophysiological associations between GI disorders and the PD mechanical and infectious complications. We believe that GI disorders might be an important factor compromising the longevity of PD technique.

\section{Ethics Statement}

The authors have no ethical conflicts to disclose. 


\section{Disclosure Statement}

The authors have no conflicts of interest to declare.

\section{Funding Sources}

None.

\section{Author Contributions}

G.K. participated in the literature research, the processing of the data and the writing and the submission of the paper. J.A. participated in the literature research and the processing of the data. E.C.C. and F.S. participated in the writing and editing of the paper. D.A. participated in the processing of the data and the editing of the paper.

\section{References}

1 Zuvela J, Trimingham C, Le Leu R, Faull R, Clayton P, Jesudason S, Meade A: Gastrointestinal symptoms in patients receiving dialysis: a systematic review. Nephrology (Carlton) 2018, Epub ahead of print.

2 Svedlund J, Sjödin I, Dotevall G: GSRS-a clinical rating scale for gastrointestinal symptoms in patients with irritable bowel syndrome and peptic ulcer disease. Dig Dis Sci 1988;33:129_ 134.

3 Dimenäs E, Glise H, Hallerbäck B, Hernqvist $\mathrm{H}$, Svedlund J, Wiklund I: Quality of life in patients with upper gastrointestinal symptoms. An improved evaluation of treatment regimens? Scand J Gastroenterol 1993;28: 681-687.

4 Li Y, Dong J, Zuo L: Is subjective global assessment a good index of nutrition in peritoneal dialysis patients with gastrointestinal symptoms? Perit Dial Int 2009;29(suppl 2):S78S82.

5 Adam B, Liebregts T, Saadat-Gilani K, Vinson B, Holtmann G: Validation of the gastrointestinal symptom score for the assessment of symptoms in patients with functional dyspepsia. Aliment Pharmacol Ther 2005;22:357363.

6 Longstreth GF, Thompson WG, Chey WD, Houghton LA, Mearin F, Spiller RC: Functional bowel disorders. Gastroenterology 2006;130:1480-1491.

7 Lewis SJ, Heaton KW: Stool form scale as a useful guide to intestinal transit time. Scand J Gastroenterol 1997;32:920-924.

8 Riegler G, Esposito I: Bristol scale stool form. A still valid help in medical practice and clinical research. Tech Coloproctol 2001;5:163164.

9 Dong R, Guo ZY, Ding JR, Zhou YY, Wu H: Gastrointestinal symptoms: a comparison between patients undergoing peritoneal dialysis and hemodialysis. World J Gastroenterol 2014;20:11370-11375.

10 Lee YC, Hung SY, Wang HH, Wang HK, Lin CW, Chang MY, et al: Different risk of common gastrointestinal disease between groups undergoing hemodialysis or peritoneal dialysis or with non-end stage renal disease: a nationwide population-based cohort study. Medicine (Baltimore) 2015;94:e1482.

11 Salamon K, Woods J, Paul E, Huggins C: Peritoneal dialysis patients have higher preva- lence of gastrointestinal symptoms than hemodialysis patients. J Ren Nutr 2013;23:114118.

12 Strid H, Simrén M, Johansson AC, Svedlund J, Samuelsson O, Björnsson ES: The prevalence of gastrointestinal symptoms in patients with chronic renal failure is increased and associated with impaired psychological general well-being. Nephrol Dial Transplant 2002;17: 1434-1439.

13 Strid H, Fjell A, Simrén M, Björnsson ES: Impact of dialysis on gastroesophageal reflux, dyspepsia, and proton pump inhibitor treatment in patients with chronic renal failure. Eur J Gastroenterol Hepatol 2009;21:137142.

14 Strid H, Simrén M, Stotzer PO, Abrahamsson $\mathrm{H}$, Björnsson ES: Delay in gastric emptying in patients with chronic renal failure. Scand J Gastroenterol 2004;39:516-520.

15 Van V, Schoonjans RS, Struijk DG, Verbanck JJ, Vanholder RC, Van B, Lefebvre RA, De V, Lameire NH: Influence of dialysate on gastric emptying time in peritoneal dialysis patients. Perit Dial Int 2002;22:32-38.

16 Hubalewska A, Stompór T, Płaczkiewicz E, Staszczak A, Huszno B, Sułowicz W, Szybiński $\mathrm{Z}$ : Evaluation of gastric emptying in patients with chronic renal failure on continuous ambulatory peritoneal dialysis using $99 \mathrm{mTc}$-solid meal. Nucl Med Rev Cent East Eur 2004;7: 27-30.

17 Fernström A, Hylander B, Grybäck P, Jacobsson H, Hellström PM: Gastric emptying and electrogastrography in patients on CAPD. Perit Dial Int 1999;19:429-437.

18 Guz G, Bali M, Poyraz NY, Bagdatoglu O, Yeğin ZA, Doğan I, Atasever T, Sert S, Sindel S: Gastric emptying in patients on renal replacement therapy. Ren Fail 2004;26:619624.

19 Dejardin A, Robert A, Goffin E: Intraperitoneal pressure in PD patients: relationship to intraperitoneal volume, body size and PD-related complications. Nephrol Dial Transplant 2007:22:1437-1444.

20 Kim MJ, Kwon KH, Lee SW: Gastroesophageal reflux disease in CAPD patients. Adv Perit Dial 1998;14:98-101.

21 Hylander BI, Dalton CB, Castell DO, Burkart J, Rössner S: Effect of intraperitoneal fluid volume changes on esophageal pressures: studies in patients on continuous ambulatory peritoneal dialysis. Am J Kidney Dis 1991;17: 307-310.

22 Anderson JE, Yim KB, Crowell MD: Prevalence of gastroesophageal reflux disease in peritoneal dialysis and hemodialysis patients. Adv Perit Dial 1999;15:75-78.

23 Song HJ, Kim SM, Lee YM, Hwang JA, Moon $\mathrm{KM}$, Moon CG, et al: Is there a difference in the prevalence of gastroesophageal reflux disease between peritoneal dialysis and hemodialysis patients? Korean J Gastroenterol 2013; 62:206-212.

24 Lee SW, Song JH, Kim GA, Yang HJ, Lee KJ, Kim MJ: Effect of dialysis modalities on gastric myoelectrical activity in end-stage renal disease patients. Am J Kidney Dis 2000;36: 566-573.

25 Aguilera A, Codoceo R, Bajo MA, Diéz JJ, del Peso G, Pavone M, et al: Helicobacter pylori infection: a new cause of anorexia in peritoneal dialysis patients. Perit Dial Int 2001; 21(suppl 3):S152-S156.

26 Schoonjans R, Van VB, Vandamme W, Van HN, Verdievel H, Vanholder R, Lameire N, De VM: Dyspepsia and gastroparesis in chronic renal failure: the role of Helicobacter pylori. Clin Nephrol 2002;57:201207.

27 Huang KW, Leu HB, Luo JC, Chan WL, Hou MC, Lin HC, et al: Different peptic ulcer bleeding risk in chronic kidney disease and end-stage renal disease patients receiving different dialysis. Dig Dis Sci 2014;59:807813.

28 Chen YT, Yang WC, Lin CC, Ng YY, Chen JY, Li SY: Comparison of peptic ulcer disease risk between peritoneal and hemodialysis patients. Am J Nephrol 2010;32:212218.

29 Su CY, Pei J, Lu XH, Tang W, Wang T: Gastrointestinal symptoms predict peritonitis rates in CAPD patients. Clin Nephrol 2012 77:267-274.

30 Yip T, Tse KC, Lam MF, Cheng SW, Lui SL, Tang S, et al: Colonic diverticulosis as a risk factor for peritonitis in Chinese peritoneal dialysis patients. Perit Dial Int 2010;30:187-191.

$31 \mathrm{Wu}$ G, Khanna R, Oreopoulos DG: Is extensive diverticulosis of the colon a contraindication to CAPD? Perit Dial Bull 1983;3:180183 
32 Tranæus A, Heimbürger O, Granqvist S: Diverticular disease of the colon: a risk factor for peritonitis in continuous peritoneal dialysis. Nephrol Dial Transplant 1990;5:141147.

33 Caravaca F, Ruiz-Calero R, Dominguez C: Risk factors for developing peritonitis caused by micro-organisms of enteral origin in peritoneal dialysis patients. Perit Dial Int 1998; 18: 41-45.

34 del Peso G, Bajo MA, Gadola L, Millán I, Codoceo R, Celadilla O, et al: Diverticular disease and treatment with gastric acid inhibitors do not predispose to peritonitis of enteric origin in peritoneal dialysis patients. Perit Dial Int 2001;21:360-364.

35 Afsar B, Elsurer R, Bilgic A, Sezer S, Ozdemir $\mathrm{F}$ : Regular lactulose use is associated with lower peritonitis rates: an observational study. Perit Dial Int 2010;30:243-246.
36 Mimidis K, Mourvati E, Kaliontzidou M, Papadopoulos V, Thodis E, Kartalis G, Vargemezis V, et al: Efficacy of polyethylene glycol in constipated CAPD patients. Perit Dial Int 2005;25:601-603.

37 Sutton D, Ovington S, Engel B: A multi-centre, randomised trial to assess whether increased dietary fibre intake (using a fibre supplement or high-fibre foods) produces healthy bowel performance and reduces laxative requirement in free living patients on peritoneal dialysis. J Ren Care 2014;40:157163.

38 Yasuda G, Shibata K, Takizawa T, Ikeda Y, Tokita Y, Umemura S, Tochikubo O, et al: Prevalence of constipation in continuous ambulatory peritoneal dialysis patients and comparison with hemodialysis patients. Am J Kidney Dis 2002;39:1292-1299.
39 Zhang J, Huang C, Li Y, Chen J, Shen F, Yao Q, et al: Health-related quality of life in dialysis patients with constipation: a cross-sectional study. Patient Prefer Adherence 2013;7: 589-594.

40 Singharetnam W, Holley JL: Acute treatment of constipation may lead to transmural migration of bacteria resulting in gram-negative, polymicrobial, or fungal peritonitis. Perit Dial Int 1996; 16:423-425.

41 Boobés K, Rosa RM, Batlle D: Hypokalemia associated with acute colonic pseudo-obstruction in an ESRD patient. Clin Nephrol 2017;87:152-156.

42 Aguilera A, Bajo MA, Espinoza M, Olveira A, Paiva AM, Codoceo R, et al: Gastrointestinal and pancreatic function in peritoneal dialysis patients: their relationship with malnutrition and peritoneal membrane abnormalities. Am J Kidney Dis 2003;42:787-796. 